\title{
Rubem Alves: educação x religião
}

\author{
Rubem Alves: education $\mathrm{x}$ religion \\ Rubem Alves: educación $\mathrm{x}$ religión
}

Recebido: 17/08/2021 | Revisado: 22/08/2021 | Aceito: 25/08/2021 | Publicado: 28/08/2021

\author{
Maria de Jesus Reis Silva \\ ORCID: https://orcid.org/0000-0002-9203-2020 \\ Faculdade Unida, Brasil \\ E-mail: maria-dejesusreis@hotmail.com \\ Maria do Perpétuo Socorro Ferreira dos Anjos \\ ORCID: https://orcid.org/0000-0002-7682-7499 \\ Fraga Instituto de Educação, Cultura e Pesquisa, Brasil \\ E-mail: socorro-ferreira@hotmail.com
}

\begin{abstract}
Resumo
A preocupação de Rubem Alves com a educação e a religião está demonstrada em suas obras. Percebe-se que sua literatura possui um fundo psicanalítico agregado à vida humana em sociedade, na qual demonstra o seu cuidar nas situações do fazer pedagógico. Esta pesquisa tem por objetivo refletir sobre aspectos relevantes que, em suas obras, relatam a afetividade do professor no ato de ensinar. Está constituída por pesquisa bibliográfica projetada em uma metodologia de natureza qualitativa. Os Resultados mostram que há publicações que vão ao encontro do pensamento de Alves. Os dados enumerados apontam para as proposições do autor sobre a confluência entre educação e religião. Sua linguagem está revestida de subjetividade, o que faz entender toda sua inquietude diante do mundo. Em relação à educação escolar apresenta subsídios quanto ao papel do professor incentivador e afetivo no processo educativo, sobretudo, na prática do ensino religioso. Nas considerações finais, destaca-se o pioneirismo de Alves vinculado à educação e à religião, pois o seu pensar é um referencial aos fatos sociais da sociedade contemporânea.
\end{abstract}

Palavras-chave: Afetividade; Educação; Religião; Subjetividade.

\begin{abstract}
Rubem Alves' concern with education and religion is demonstrated in his works. It is noticed that his literature has a psychoanalytical background added to human life in society, in which he demonstrates his care in situations of pedagogical practice. This research aims to reflect on relevant aspects that, in their works, report the teacher's affectivity in the act of teaching. It consists of bibliographic research designed in a qualitative methodology. The Results show that there are publications that meet Alves' thinking. The enumerated data point to the author's propositions about the confluence between education and religion. His language is coated with subjectivity, which makes us understand all his uneasiness before the world. In relation to school education, he presents subsidies regarding the role of the encouraging and affective teacher in the educational process, especially in the practice of religious teaching. In the final considerations, the pioneering spirit of Alves linked to education and religion is highlighted, as his thinking is a reference to the social facts of contemporary society.
\end{abstract}

Keywords: Affection; Education; Religion; Subjectivity.

\section{Resumen}

En sus obras. Se advierte que su literatura tiene un trasfondo psicoanalítico agregado a la vida humana en sociedad, en el que demuestra su cuidado en situaciones de práctica pedagógica. Esta investigación tiene como objetivo reflexionar sobre aspectos relevantes que, en sus trabajos, reportan la afectividad del docente en el acto de enseñar. Consiste en una investigación bibliográfica diseñada en una metodología cualitativa. Los Resultados muestran que hay publicaciones que responden al pensamiento de Alves. Los datos enumerados apuntan a las proposiciones del autor sobre la confluencia entre educación y religión. Su lenguaje está revestido de subjetividad, lo que nos hace comprender todo su malestar frente al mundo. En relación a la educación escolar, presenta subsidios en cuanto al rol del docente alentador y afectivo en el proceso educativo, especialmente en la práctica de la enseñanza religiosa. En las consideraciones finales, se destaca el espíritu pionero de Alves vinculado a la educación y la religión, ya que su pensamiento es una referencia a los hechos sociales de la sociedad contemporánea.

Palabras clave: Afectividad; Educación; Religión; Subjectividad. 


\section{Introdução}

Falar de educação é pensar em transformação, mudança de pensamento e, principalmente de vida. Por meio da educação é possível ascender tanto cultural quanto social e economicamente. Por isso mesmo, a educação se utiliza de pensadores, escritores e profissionais que mesmo não abordando diretamente a prática pedagógica serviram de base para a prática pedagógica hoje utilizada. Dentre os que incrementaram a prática pedagógica do mundo ocidental temos: Freud (18561939), Piaget (1896-1980) e Vygotsky (1896-1934).

O equivalente nacional é o escritor, filósofo, teólogo, professor e Rubem Alves, falecido na segunda década do século XXI. Teve como referência os três teóricos supracitados. Como escritor, além dos livros de sua contribuição com livros que auxiliaram com a prática pedagógica, teve como ponto alto histórias que encantam tanto pela sua simplicidade quanto pelos incontáveis ensinamentos para o público infantil. A presente pesquisa, de caráter descritivo, objetiva refletir sobre a visão de Rubem Alves com relação à afetividade no ato docente no ensino religioso que referenciou os ensinamentos para outras áreas da educação.

Alves (2011, p. 22) acredita que "a inteligência é a ferramenta que o corpo usa para transformar os seus sonhos em realidade. É preciso escutar as crianças para que sua inteligência desabroche". Elenca como ato fundamental do processo de ensinar o "escutar claro". O professor antes de aprender a falar claro de forma que o aluno consiga compreendê-lo deve, principalmente, escutar e sentir o seu aluno para que, ao compreendê-lo consiga ensinar de forma mais clara.

Aprende-se mais quando não se sabe que está aprendendo. No exemplo de aprendizado da fala fica clara essa concepção, pois o aprendizado de uma língua nativa é feito por meio da assimilação da língua falada ao seu redor. Ao chegar à escola, quando se aprenderá a língua formal a criança traz consigo um conjunto de regras já internalizadas, ou seja, sabe qual a estrutura da frase (no português sujeito, verbo, objeto), conhece os tempos verbais. Aprenderá apenas o código escrito, a função morfológica e a função sintática. Uma criança que é bem escutada consegue segurança suficiente para alçar voos em sua vida acadêmica, uma vez que não foi tolhida, mas sim compreendida.

Se fôssemos aprender a língua nativa de forma científica, primeiro entendendo regras, estudos sintáticos e morfológicos, esse aprendizado não se daria de forma natural, fazendo com que demorasse muito mais tempo para se adquirir a língua nativa. O caso concreto se dá, quando pensamos na criança surda que por não ouvir não assimilam a língua e só irá aprendê-la ao chegar à escola de maneira formal o que dificulta, sobremaneira, o seu aprendizado, já que a fala não é funcional pela falta da audição.

Portanto, o fato social vem antes do fato científico. Quando você primeiro assimila uma língua depois assimila a fala e só então aprenderá regras desta mesma língua, significa que o aprender empírico, veio antes do aprender científico, como isso se pode assegurar que os saberes científicos são atrelados aos saberes empíricos e estes vão sendo utilizados para outras experiências e outros fatos científicos. Muitos aprendizados se tornam obsoletos devido à evolução científica. Um exemplo claro é que há 40 anos o adolescente necessitava de cursos de datilografia para conseguir uma colocação profissional. Hoje, apesar de o computador ter a mesma configuração de teclas da máquina de escrever o mesmo é uma evolução científica do já obsoleto objeto. Se tornando essencial o seu domínio para pleitear postos profissionais.

Por isso, "tão importante quanto a aprendizagem do uso das ferramentas existentes é a arte de construir novas ferramentas" (Alves, 2011). Além de seu posicionamento a respeito do conhecimento científico, suas obras denotam um profundo teor psicanalítico onde se encontram elementos ligando a educação e a religião à vida humana e à sociedade, formando uma cadeia relacionada e interdependente. Sua inquietude diante do mundo se traduz em uma rica produção subjetiva, que serviu como base para permear o papel central do professor no processo educativo. 
Alves em seu acervo literário apresente temas recorrentes como: subjetividade, religião, ciência, afetividade e psicanálise. Em todos é possível perceber uma conexão com a educação. Além disso, diante das várias abordagens sobre os fundamentos do ser humano e de sua convivência no dia a dia é factível que há uma preocupação com a relação professor/aluno na aprendizagem escolar. Desta forma, na medida em que seus textos são direcionados às particularidades da dinâmica do saber e da subjetividade, fica ratificada a mediação necessária entre o sujeito e o outro.

Ainda sobre a questão educacional, Alves se fundamenta nas ideias psicanalíticas do imaginário e do caráter simbólico defendido por Freud. Para ele as formas como as ferramentas começam com o sonho. O corpo sonha. Freud acreditava que somos voltados para o princípio do prazer e com isso, no sonho alimentamos o nosso imaginário, tornando-se o sonho o nosso pequeno paraíso. Se fôssemos poderosos com os deuses poderíamos realizar todos os nossos sonhos, pois para isso bastaria dizê-los em voz alta posto que o sonho da ordem a inteligência, pois, o sonho dá ordens à inteligência. (Alves, 2011, 15).

Segundo o autor, a psicanálise, como ciência pouco ortodoxa, esclarece que o lugar para o discurso das ausências, discursos dos sonhos, das esperanças é na interioridade do indivíduo, uma vez que explode, emerge, rompe, sem permissão do indivíduo e provoca uma revolução no mundo tranquilo e racional estabelecido em nossas rotinas (Alves, 1980, p. 18).

Alves salienta a importância das escolas como propagadoras do conhecimento científico envidando esforços para que esse conhecimento seja repassado de forma competente, uma vez que a ciência, porque a ciência auxilia o belo e o belo (subjetivo) auxilia a ciência (objetivo). É um meio indispensável para que os sonhos sejam realizados. Sem conhecimento não se pode plantar nem cuidar dos jardins. (Alves, 1999, p. 26).

Diante de evidências que ligam o trabalho de Rubens Alves a afetividade, subjetividade, psicanálise e a educação, formula-se a pergunta: É possível utilizar o seu pensamento na prática pedagógica do ensino religioso?

Em relação à metodologia Gil (2008, p. 50) "a pesquisa bibliográfica é desenvolvida a partir de material já elaborado, constituído de livros e artigos científicos. Embora em quase todos os estudos seja exigido algum tipo de trabalho desta natureza, há pesquisas desenvolvidas exclusivamente a partir de fontes bibliográfica".

\section{Metodologia}

Este estudo está constituído por pesquisa bibliográfica de natureza qualitativa focada na leitura de livros, de revistas e de artigos científicos, além de materiais encontrados nas plataformas eletrônicas.

Nesse sentido, a análise documental propiciou uma ampla gama de material, que segundo Lüdke e André embora pouco explorada pode se constituir como uma técnica valiosa de abordagem de dados qualitativos, pois analisar os dados qualitativos significa trabalhar todo material obtido durante a pesquisa, ou seja, os relatos das observações, as transcrições da pesquisa e as análises dos documentos e as demais informações disponíveis. Nesse sentido, a grande bibliografia de Alves impôs uma investigação rigorosa do material a ser escolhidos para análise (Lüdke \& André, p. 38). Portanto, do material disponível pesquisado foram selecionados para este estudo 10 (dez) artigos científicos encontrados na plataforma eletrônica. 
Tabela 1. Estudos selecionados a partir das variáveis: Autor, Título, Ano de Publicação e Objeto de Estudo.

\begin{tabular}{|c|c|c|}
\hline Autor(es) & Título/Ano Publicação & Objeto de estudo \\
\hline Resende, A. C. A. & $\begin{array}{l}\text { Subjetividade e cultura: a contribuição da psicanálise ao } \\
\text { debate }-2006\end{array}$ & A objetividade e a subjetividade. \\
\hline Junqueira, S. R. A. & $\begin{array}{l}\text { Capacitação do Professor de ensino religiosos: formar o } \\
\text { formador!? - } 2018\end{array}$ & $\begin{array}{l}\text { A formação docente para o Ensino } \\
\text { Religioso. }\end{array}$ \\
\hline $\begin{array}{l}\text { Silva, A. W. C., Barbosa, L. } \\
\text { F. S.; Zacarias, R. }\end{array}$ & $\begin{array}{l}\text { Antropologia Teológica: Pensar o Humano na Universidade } \\
-2017\end{array}$ & O ser humano, quem é ele? \\
\hline $\begin{array}{l}\text { Nascimento, J; A.; Santos, } \\
\text { M. G. T. }\end{array}$ & $\begin{array}{l}\text { Vida e Obra de Rubem Alves: Visões e Contribuições para } \\
\text { a Educação - } 2016\end{array}$ & Percepção de valores na vida cotidiana. \\
\hline Zabatiero, J. P. T. M. & $\begin{array}{l}\text { Linguagem Religiosa: constituição, tensividade, evento - } \\
2019\end{array}$ & $\begin{array}{l}\text { Reflexões sobre a linguagem religiosa no } \\
\text { campo das Ciências das Religiões. }\end{array}$ \\
\hline Valentini, D. B. & $\begin{array}{l}\text { Impasses Pedagógicos Contemporâneos: um estudo sobre } \\
\text { orientação vocacional em escolas }-2012\end{array}$ & $\begin{array}{l}\text { O devir histórico e a cronologia do tempo } \\
\text { linear. }\end{array}$ \\
\hline Ivic, I., Coelho, E. P. (org.). & Lev Semionovich Vygotsky - 2010 & A interação sociocultural \\
\hline Giddens, A. & Sociologia -2005 & A religião e as manifestações sociais. \\
\hline Vigotski, L. S. & O desenvolvimento psicológico na infância - 1999 & $\begin{array}{l}\text { A fonte das emoções nos processos } \\
\text { emocionais. }\end{array}$ \\
\hline Piaget, J. & Psicologia da inteligência - 1977 & $\begin{array}{l}\text { O afeto e a formação de estruturas } \\
\text { cognitivas. }\end{array}$ \\
\hline
\end{tabular}

Fonte: Autores (2021).

\section{Referencial Teórico}

O dicionário Etimológico (Cunha, 2000, p. 673) conceitua religião como substantivo feminino que pressupõe dois significados: 1 - "crença na existência de uma força ou forças sobrenaturais considerada(s) como criadora(s) do Universo, e como tal deve(m) ser adoradas e obedecida(s)". Portanto, a religião tem a ver com o individual, sua relação com o divino, coletiva, seu comportamento perante os indivíduos que possuem a mesma crença e, social o que representa essa crença em sociedade em que a pessoa vive. Assim sendo, as religiões, também, servem como forma de ascensão social.

Segundo Giddens (2005) a religião é alicerce para um grande número de manifestações sociais, entre elas a literatura, a música e a arte que sofrem influência das tradições religiosas sempre que esta comunidade está intimamente conectada a ela.

Então, como seria possível ensinar religião se muitas vezes ela não está inserida no contexto de vivência da criança? Alves se apropria da afetividade como forma de fazer com que o aprendizado seja mais efetivo. Mas, como o conceito de religião para Alves não passa de mera intuição ele prefere encontrar nos grandes filósofos as várias definições que se encaixam em um momento ou em outro na sua temática. Segundo ele, a marca de todas as religiões é o esforço para pensar a realidade toda a partir de que as exigências da vida façam sentido. Porém, o encanto foi quebrado. A ciência e a tecnologia construíram um mundo onde Deus não era mais necessário como hipótese de trabalho, sendo uma das marcas do saber científico um ateísmo metodológico. Embora a religião não tenha desaparecido perdeu espaço na vida cotidiana do indivíduo (Alves, 2007, p. 3).

A Lei de Diretrizes e Bases da Educação Nacional trouxe para o Ensino Religioso (ER) uma versão pedagógica elencada em seu artigo 13, LDBEN nº 9394/96.

Segundo Junqueira (2018) a LDB é uma proposta que busca, além da visão de totalidade, a superação da reprodução do conhecimento. Nesse sentido, afirma que: 
Passou-se a compreender que o indivíduo participa da construção do conhecimento e de que todo o organismo é na realidade formas de movimento, onde matéria e mente são aspectos diferente e inseparáveis de um mesmo conjunto, reconhecendo que o indivíduo pratica a construção do conhecimento não apenas com uso predominante do raciocínio e da percepção do mundo exterior pelos sentidos, mas também usando as sensações, os sentimentos, as emoções e a intuição para aprender. Nada pode ser fragmentado ou separado.

Deste modo, o ser humano, sendo criador de cultura, tornar-se-á sujeito por meio da reflexão sobre seu ambiente, na medida em que se integra com as condições de seu contexto de vida, compreendendo cultura como resultado da atividade humana e do esforço em estabelecer suas relações interpessoais (Junqueira, 2018).

\subsection{Racionalidade x Afetividade}

Pensar que afetividade e racionalidade estão correlacionadas parece um contrassenso, porém na educação se torna praticamente impossível a aprendizagem do conhecimento racional se quem a afetividade seja parte deste.

Para Neumann e Velozo (2019) ao enxergar as coisas de forma separada umas das outras, como educação e vida, há um comprometimento nas relações interpessoais, pois a educação existe a partir da relação do indivíduo com o outro. Quando se vê o todo em fragmentos, tende-se a atribuir responsabilidade apenas a um elemento isolado. Os autores enfatizam que:

Trazer a afetividade junto à racionalidade à tona na educação implica pensar estudantes e professoras ou professores como indivíduos que vivenciam experiências que os constroem e reconstroem continuamente. A ideia de transformação tem por base o movimento do próprio significado. Uma sociedade e educação que cogitam, de um lado, a ideia de mudança e de diferenças e, de outro, acreditam que os elementos que compõem a vida dos indivíduos estão separados, tende a suscitar conflitos, pois a separação implica ausência de movimento e de mudança (Neumann \& Velozo, 2019).

Para Piaget vida afetiva e vida cognitiva são inseparáveis embora distintas, pois todo intercâmbio como meio presume, ao mesmo tempo estruturação e valorização. Portanto, para sermos capazes de relacionar necessitamos vivenciar certos sentimentos, bem como não existem afeições sem o mínimo de compreensão. Piaget ressalta que o afeto pode acelerar ou retardar a formação de estruturas cognitivas (Piaget, 1977, p. 16). O afeto está diretamente relacionado ao interesse, à motivação e a necessidade pela aprendizagem, por isso um complementa o outro.

Dentro desta perspectiva, Vigotski (1999, p. 82) "a fonte das emoções está nas reações orgânicas que acompanham nossos processos emocionais". Durante o processo de ensino e aprendizagem é necessária uma perfeita interação entre professor e aluno onde a afetividade é a responsável direta pelo desenvolvimento de seus processos cognitivos, afinal já dizia Alves (1999, p. 24) "tudo começa com um ato de amor".

Nesse contexto, entre uma das principais ideias de Alves sobre a afetividade, está a ciência da psicanálise. O autor enfatiza que a psicanálise nos dá um alerta quanto ao lugar na interioridade de nós mesmos que têm o discurso sobre as ausências, discursos dos sonhos, das esperanças, explodindo, emergindo, irrompendo sem permissão, para invadir e embaraçar o mundo tranquilo, racional e estabelecido de nossas rotinas institucionais (Alves, 1980, p. 18).

\subsection{Pensamento Pedagógico: objetividade e subjetividade}

Com relação a este ponto é importante ressaltar que para compreendermos o ser humano, faz-se necessário analisá-lo como ser aberto, relacional e simbólico, cuja produção cultural é marcada pelo pluralismo, inclusive na sua dimensão religiosa. A construção simbólica passa a ser uma expressão da procura de explicação às causalidades daquilo que se vive. São as relações sociais que, além de dar o sentido de pertença, estabelecem os limites na convivência social. Sem parâmetros 
relacionais, não há como se tornar pessoa humana. A produção simbólica tem a função de superar as contradições e desenvolver o sentimento de pertencimento a um grupo, evidenciando seu caráter harmonizador (Silva et al., 2017).

Para Valentini (2012) contemporâneo é aquele que não cessa de interpelar seu tempo, em especial as "cesuras", que definem um antes e um depois no tempo presente, que produzem uma descontinuidade. É, também, aquele que não adere as regras, experiências e valores sem antes interpretá-los, sendo capaz de distanciar-se do instante - sempre inapreensível -, e operar tudo com aspectos do passado quanto do devir histórico; é aquele capaz de "introduzir uma desomogeneidade" na cronologia do tempo linear.

Para Nascimento e Santos (2016) Rubem Alves foi um educador contemporâneo, pautou suas falas e reflexões no objetivo de provocar a percepção de valores presentes e necessários à vida dos indivíduos, pois entendia a vida cotidiana como fatores que contribuem, significativamente, para a formação do ser humano em sua essência, por meio, não só da educação escolar, mas também da educação para a vida na formação do educando.

Segundo Resende:

O debate acerca do que se convencionou nomear amplamente de "subjetividade" vem de longe. Os esforços para enfrentar o desafio da compreensão da "vida subjetiva", estabeleceram-se desde sempre no contraponto com a "vida objetiva", explicitando duas dimensões fundamentais da condição humana: a objetividade -externa, material, coletiva, prática - e a subjetividade - interna, espiritual, individual, emocional. Esses esforços podem ser apreendidos, ontem como hoje, em boa parte da discussão acerca da relação entre indivíduo e sociedade, que sempre ressoou a relação entre a subjetividade e a objetividade (Resende, 2006).

Ao tratar objetividade e subjetividade a psicanálise é capaz de isolar o sujeito em apenas um aspecto do indivíduo, ou seja, na sua subjetividade. Na prática pedagógica o professor precisa lidar com a dualidade: razão x indivíduo, sob pena de não cumprir seu papel fundamental que é de facilitar a aprendizagem, uma vez que é na subjetividade que obterá caminho para que o aluno chegue ao conhecimento.

\subsection{Linguagem e Religião}

Alves projetando suas premissas a partir de outros olhares, faz com que educação e religião se completem e dialoguem entre si. Pois, seu pensamento perpassa por diferentes abordagens dos campos disciplinares tais como: a Antropologia, a Psicanálise, a Ciência, a Filosofia, inclusive a Teologia.

De acordo com Ivic e Coelho (2010, p. 19) a análise de Vygotsky sobre as relações entre desenvolvimento e aprendizagem, no caso da aquisição da linguagem, nos conduz a definir o primeiro modelo de desenvolvimento: em um processo natural, a aprendizagem aparece como um meio de reforçar esse processo, pondo à sua disposição os instrumentos criados pela cultura que ampliam as possibilidades naturais do indivíduo e reestruturam suas funções mentais. O papel dos adultos, como representantes da cultura no processo de aquisição da linguagem pela criança e de apropriação por ela de uma parte da cultura - a língua -, conduz à descrição de um novo tipo de interação. Portanto, dois tipos de interação se manifestam, muitas vezes, sob a forma de interação sociocultural.

Para tanto, há diferentes conceitos sobre o campo da religiosidade. Porém, por sua complexidade, Zabatiero (2019) considera dois conceitos importantes: o conceito mais amplo chamado de "discurso constituinte" e o conceito de "evento".

Segundo o autor discurso constituinte destaca a similaridade entre os diferentes tipos de linguagem assim classificados, porém para destacar uma particularidade do discurso religioso, recorre-se ao conceito de "tensividade". Destaca, também, o conceito de "evento" que visa responder a duas questões principais: a natureza do archéion do discurso constituinte e a de natureza do sagrado. Para Zabatiero (2019) "o discurso constituinte é, então, um "gênero" do discurso, ou seja, uma 
forma peculiar de articulação entre conteúdo e sociedade, que procura captar as características comuns de um determinado conjunto de tipos específicos de discurso". Portanto,

É própria do texto religioso a busca da permanência da fusão entre sujeito e objeto - sendo que o "objeto" é, em várias religiões, entendido como "sujeito". Para que haja essa permanência, é necessário que o deslumbramento inicial da experiência seja relativizado e ordenado discursivamente (compreensão similar é construída nas ciências das religiões, tema a que se voltará mais adiante). Diferentes tipos de comunidades discursivas religiosas constroem formas específicas de manutenção da fusão sujeito-objeto, mais comumente mediante formas rituais e litúrgicas que possibilitem a repetição da experiência de deslumbramento. Dessa forma, a "ambição ética" da Religião é alimentada e concretizada, provocando distintas ressignificações do mundo e seus sentidos (Zabatiero, 2019).

Nesse contexto, Alves (2007) enfatiza que a religião nasce pelo poder que os homens têm de dar nomes às coisas, fazendo uma separação entre coisas de importância secundária e coisas nas quais seu destino, sua vida e sua morte, se dependuram. Assim, fazendo uma abstração dos sentimentos e experiências pessoais, que acompanham o encontro com o sagrado, a religião se apresenta como certo tipo de linguagem, de discurso e rede de símbolos.

Quanto à religiosidade destaca a maneira peculiar da apresentação dos símbolos quando enfatiza:

De tanto serem repetidos e compartilhados, de tanto serem usados, com sucesso, à guisa de receitas, nós os reificamos, passamos a tratá-los como se fossem coisas. Todos os símbolos que são usados com sucesso experimentam esta metamorfose. Deixam de ser hipóteses da imaginação e passam a ser tratados como manifestações da realidade. Certos símbolos derivam o seu sucesso do seu poder para congregar os homens, que os usam para definir a sua situação e articular um projeto comum de vida. [...]. Os símbolos vitoriosos, e exatamente por serem vitoriosos, recebem o nome de verdade, enquanto que os símbolos derrotados são ridicularizados como superstições ou perseguidos como heresias. E nós, que desejamos saber o que é a religião, que já sabemos que ela se apresenta como uma rede de símbolos, temos de parar por um momento para nos perguntar sobre o que ocorreu com aqueles que herdamos (Alves, 1980, p. 39).

Alves escreveu vários livros relacionados ao tema religiosidade, dentre os quais destacamos: O que é Religião, o Deus que eu conheço e o Enigma da Religião. Nessas obras Alves retrata a sua relação com a religiosidade destacando a afetividade como forma de atingir o indivíduo tanto no aspecto pedagógico quanto no religioso.

\subsection{Ensino Religioso e Afetividade Docente}

Questões envolvendo a diversidade religiosa na sociedade contemporânea tornou-se um fenômeno mundial, uma vez que a religiosidade é vivida tanto em contextos sociais quanto individual. O Brasil possui uma cultura caracterizada pela diversidade cultural, portanto, o ER deverá compreender, também, as demandas de sua herança cultural religiosa. Assim, pela complexidade humana, esse é um dos desafios que se apresenta aos professores na docência do ER no cotidiano escolar.

Frente às mudanças ocorridas no espaço escolar atual o agir pedagógico docente, relacional e subjetivo, se apresenta como um instrumento para a aprendizagem do aluno e para a apropriação ativa de saberes, portanto, centrada na vida do indivíduo.

Nessa perspectiva, Passos afirma que "a educação do cidadão é um processo complexo que inclui múltiplos aspectos, inclusive o religioso, sendo este último um dado antropológico e sociocultural presente na história da humanidade" (Passos, 2007, p. 33).

Daí a importância de se compreender o significado da linguagem mediadora no campo da religiosidade e da subjetivação do indivíduo no mundo, conforme destaca Rubem Alves, em suas obras. 
As dificuldades no ensino religioso existem para o professor, pois o problema da docência, nas escolas, envolve questões específicas, principalmente, as culturais. No entanto, para que se possam estabelecer mudanças significativas na prática pedagógica é preciso foco na historicidade humana.

Deste modo, ao ponderar sobre o ato de ensinar compreende-se que exista um conjunto de ações que são planejadas e organizadas com as demais áreas do conhecimento, oportunizando aos alunos uma aprendizagem significativa. Com efeito, em se tratando de educação escolar a Constituição Federal de 1988, reconhece no art. 210, a necessidade de que sejam "fixados conteúdos mínimos para o ensino fundamental, de maneira a assegurar formação básica comum e respeito aos valores culturais e artísticos, nacionais e regionais" (Brasil, CF,1988).

Nesse sentido, cada escola tem identidade própria, na qual é constituída por uma trama de circunstâncias em que se cruzam diferentes fatores. Possui, também, uma cultura própria permeada por valores, expectativas, costumes, tradições, condições, historicamente construídos, a partir de contribuições individuais e coletivas. No interior de cada escola, realidades econômicas, sociais e características culturais estão presentes e the conferem uma identidade absolutamente peculiar. Para a Base Nacional Comum Curricular as competências gerais refletem o "conhecer-se, apreciar-se e cuidar de sua saúde física e emocional, compreendendo- se na diversidade humana e reconhecendo suas emoções e as dos outros, com autocrítica e capacidade para lidar com elas" (BNCC, 2017).

O "ensinar" para Junqueira (2018) significa oferecer condições favoráveis em certas condições de espaço e de tempo, envolvendo pessoas que mutuamente se influenciam, segundo um programa racionalmente ordenado e livremente aceito no ambiente educativo. Nesse sentido, insere-se o Ensino Religioso, a dimensão antropológica para dar ao aluno uma formação básica, social e religiosa, para consolidar a atividade educativa da escola.

\section{Resultados/Discussão}

Por se tratar de um teólogo as obras de Alves apresentam um constante diálogo entre educação e religião interligado entre a pedagogia do afeto. Sua postura reflexiva, contudo, recuperou de modo significativo o papel ético e político da subjetividade nas análises pedagógicas da condição humana, integrando-a de modo singular. A proposta pedagógica de Rubem Alves direcionou para práticas pedagógicas que favoreçam a construção do saber e do protagonismo discente.

Seu enfoque evidenciava a ótica da essência para a experiência religiosa, principalmente, quando reflete sua experiência de vida no cenário social de sua época e de um momento histórico tão complexo.

As obras de Alves servem como base para a prática pedagógica como um todo e, mais especificamente à docência do ensino religioso, pois ao trabalhar com a afetividade o professor pode consolidar a sua relação com o aluno e assim estabelecer um caminho para o despertar da religiosidade ou o aprofundamento das crenças intrínsecas ao discente. Essa tarefa torna-se mais fácil, uma vez que apesar de ser a única disciplina contemplada na Constituição Federal de 1988 como de oferta obrigatória é a única que tem matrícula facultativa fazendo com que o educando que opta por cursar a disciplina já tem predisposição a aceitar o conteúdo proposto.

\section{Considerações Finais}

Embora cientes da velocidade das transformações sociais que estão ocorrendo no mundo contemporâneo, percebemos nitidamente, o aspecto educacional de Rubem Alves pelo conhecimento científico e pela afetividade no ato de ensinar. Consistiu, assim, em compreender os aspectos que envolvem o ensino religioso sob a égide do afeto e da subjetividade na educação escolar. 
Deste modo, a formação do autor permitiu que pudéssemos conectar os vários estudiosos com que se deparou ao longo de sua trajetória de vida, propiciando ideias e formulações que podemos aplicar ao nosso tempo.

A partir do que fora observado podemos dizer que Alves, segundo suas convicções, interpretou esses pensadores sob uma nova ótica, criando “a visão Rubem Alves” de vivenciar a educação e a religião. Dessa forma, ele já observava, que o reconhecimento da educação das sensibilidades humanas poderia promover a melhoria no processo de aprendizagem do ensino religioso, principalmente, num espaço social como a escola.

Entendemos o arcabouço gerado pelo diálogo entre educação e religiosidade no contexto histórico-cultural do século vivido por Rubem Alves. Portanto, não podemos deixar de compreender que o passado, às vezes até paradoxalmente, interage com o presente e nos joga ao futuro, ao considerarmos a história da humanidade.

Por fim, concluímos que em uma posição de vanguarda, Alves preconizava a educação vinculada aos fatores da afetividade e aos relacionamentos sociais vigentes. Dessa forma, os estudos nos conduziram na compreensão sobre as práticas pedagógicas do ensino religioso no momento atual.

A temática de Rubem Alves nos traz uma gama de possibilidades para reflexões sobre a forma de ensinar com afetividade e subjetividade. Em um universo tão rico poderíamos destacar algumas de suas obras para aprofundamento de pesquisas nos temas religião, afetividade, o sagrado e sua relação pessoal com Deus propiciando uma viagem ao mundo do autor singular em levar, por meio da psicanálise, as emoções do mundo subjetivo para o mundo objetivo.

\section{Referências}

Alves, R. (1980). Conversas com quem gosta de ensinar. São Paulo: Cortez.

Alves, R. (1981). Filosofia da ciência. Introdução ao jogo e suas regras (1981). São Paulo: Brasiliense.

Alves, R. (1984). O enigma da religião. (6a ed). São Paulo: Papirus.

Alves, R. (1999). Entre a ciência e a sapiência: O dilema da educação. (4a ed.) São Paulo: Loyola.

Alves R. (2007). O que é religião. Cultural Brasiliense.

Alves, R. (2011). Educação dos sentidos e mais. São Paulo: Verus.

Brasil. (1988). Constituição da República Federativa do Brasil de $1988 . \quad$ Presidência da República. http://www.planalto.gov.br/ccivil_03/constituicao/constituicao.htm

Brasil. (1996). Lei de Diretrizes e Bases da Educação Nacional $n^{\circ}$ 9.394, de 20 de dezembro de 1996. Estabelece as diretrizes e bases da educação nacional. http://www.planalto.gov.br/ccivil_03/leis/19394.htm

Brasil. Ministério da Educação. (2017). Base Nacional Comum http://basenacionalcomum.mec.gov.br/images/BNCC_EI_EF_110518_versaofinal_site.pdf

Cunha, A. G. (2000). Dicionário Etimológico Nova Fronteira da Língua Portuguesa. (2a ed.). Rio de janeiro: Nova Fronteira.

Giddens, A. (2005). Sociologia. (4a ed.) (Sandra R. Trad). Artmed. https.://mundoeducacao.uo.com.br/sociologia/o-que-religiao.htm

Gil, A. C. (2008). Métodos e técnicas de pesquisa social. (6a ed.), Atlas.

Ivic, I. \& Coelho, E. P. (2010). Lev Semionovich Vygotsky (Romão, J. E. Trad.). MEC Fundação Joaquim Nabuco. Recife: Massangana, http://www.dominiopublico.gov.br/download/texto/me4685.pdf

Junqueira, S. R. O. (2018). Capacitação do professor de ensino religioso: formar o formador!? South American Journal of Basic Education, Technical and Technological. V. 1, N. 3. Artigo Original. https://periodicos.ufac.br/index.php/SAJEBTT/article/view/1913/1338

Lüdke, M. \& Andre, M. E. D. A. (1986). Pesquisa em educação: abordagem qualitativa. São Paulo: EPU. https://moodle.ufsc.br/pluginfile.php/2431625/mod_resource/content/1/Pesquisa\%20em\%20Educa\%C3\%A7\%C3\%A3o\%20Abordagens\%20Qualitativas\%20 vf.pdf

Nascimento, J; A. \& Santos, M. G. T. (2016). Vida e Obra de Rubem Alves: Visões e Contribuições para a Educação. https://www.unicerp.edu.br/revistas/educsaudemeioamb/p165.pdf. 
Research, Society and Development, v. 10, n. 11, e186101119525, 2021

(CC BY 4.0) | ISSN 2525-3409 | DOI: http://dx.doi.org/10.33448/rsd-v10i11.19525

Neumann, P. \& Velozo, E. L. (2019). Reflexões sobre afetividade e racionalidade na experiência educativa a partir de John Dewey. Revista Aleph, (32), 219245. https://doi.org/10.22409/revistaleph.v0i32.39315

Passos, J. D. (2007). Ensino Religioso: construção de uma proposta. São Paulo: Paulinas.

Piaget, J. (1977). Psicologia da inteligência. Rio de Janeiro: Zahar.

Resende, A. C. A. (2006, outubro 15-18). Subjetividade e cultura: a contribuição da psicanálise ao debate. Em M. T. A. Freitas (Org.), Psicologia da Educação GT (20), Associação Nacional de Pós-Graduação e Pesquisa em Educação 29 reunião anual da ANPEd, Caxambu, MG, Brasil. http://29reuniao.anped.org.br/trabalhos/trabalhos_encomendados/GT20/TE\%20-\%20GT20\%20-\%20Anita\%20A.Resende.pdf.

Silva, A. W. C., Barbosa, L. F. S. \& Zacarias, R. (2017). Antropologia Teológica: Pensar o Humano na Universidade. Ideias \& Letras. https://unisal.br/arquivos/Ebook-Antropologia-Teologica.pdf.

Valentini, D. B. (2012) Impasses Pedagógicos Contemporâneos: um estudo sobre orientação vocacional em escolas (Publicação No. 10.11606/D.48.2012.tde30072012-153354) [Dissertação de Mestrado, USP]. https://www.teses.usp.br/teses/disponiveis/48/48134/tde-30072012-153354/publico/corpo.pdf.

Vigotski, L.S. (1999). O desenvolvimento psicológico na infância. São Paulo: Martins Freire.

Zabatiero, J. P. T. M. (2019). Linguagem Religiosa: constituição, tensividade, evento. Reflexão. (44), 1-13. https://doi.org/10.24220/2447-6803v44e2019a4382 